\title{
Hematopoietic Stem Cell Transplantation, Where Have We Come and Where Do We Go
}

\author{
James Gajewski \\ Hebei Yanda Lu Daopei Hospital（consultant), China
}

Abstract

Hematopoietic cellular transplantation (HCT) has impacted medicine beyond simply treating certain diseases. Allogeneic HCT was the first documented successful immunological cellular therapy. Its usage continues to increase. The immunological disparity between donor and recipient has been associated with better antitumor efficacy as well as immunological toxicities. Through active clinical trials and research, considerable improvements in HCT therapy have been made over the past 50 years. The HCT international outcomes registry has considerably contributed to these improvements by identifying factors that could never be studied by a single center. With the use of unrelated donors, international collaboration increased as donor cell access through registries was not inhibited by international boundaries. HCT as a field pioneered the development of organizations for self-regulation that were assessing the entire program as an integrated whole rather than simply assessing facilities and providers separately.

Key words: Allogeneic Hematopoietic Transplantation

Submitted October 4, 2019; Accepted January 31, 2020; Published online May 25, 2020, Issued online August 25, 2020

Correspondence: James Gajewski, Lu Daopei Institute of Hematology, No. 22 Tongii South Road, Daxing District Beijing 100176, China, E-mail: jamesgajewski@gmail.com

\section{Introduction}

Hematopoietic stem cell transplantation (HCT) was the first documented successful cellular immunotherapy ${ }^{1-5}$. Despite repeated warnings that other therapies could replace the $\mathrm{HCT}$, usage of $\mathrm{HCT}$ continues to increase both in the United States and worldwide ${ }^{6-8}$. Predominant diagnostic indications over the past 20 years have shifted from breast cancer and chronic myelogenous leukemia to myeloma, non-Hodgkin's lymphoma, acute myelogenous leukemia, and myelodysplastic syndrome ${ }^{9-11}$. New trials are showing improvements in the efficacy of HCT in treating genetic diseases like hemoglobinopathies and debilitating systemic autoimmune diseases like multiple sclerosis and scleroderma.

The sources of hematopoietic progenitors could either be autologous, syngeneic, or allogeneic. For allogeneic HCT, the degree of HLA matching between the donor graft and recipient has historically been the most important variable determining both the risk of transplantrelated toxicity and the risk of tumor relapse ${ }^{4,12}$. Syngeneic transplants do not cause immunologic toxicities but have a relapse rate slightly less than that of autologous hematopoietic progenitor cell grafts, likely due to the graft being free of tumor cell contamination. HCT from allogeneic donors when used to treat malignances have been associated with lower relapse rates than syngeneic grafts but can also cause immunologic toxicities with morbidity and mortality risk ${ }^{13,14}$. The relapse rates are lower and the immunologic toxicities are higher in HCTs from donors who are not genotypic HLA identical siblings to the recipient.

\section{Expansion of HCT Clinical Usage Utilizing New Cell Sources}

Several studies in the 1980s demonstrated that survival results from HLA closely phenotypically matched relatives and the limited number of unrelated donors approximated HLA genotypic sibling matched results which led to the enthusiasm being generated to initiate registries of unrelated donors who are willing to donate marrow or peripheral blood progenitors ${ }^{15-18}$. This enthusiasm was further abetted by the identification of linkage disequilib- 
rium with HLA alleles, which allowed a reasonable chance of identifying unrelated donors from limited populations with registries of 100,000 donors ${ }^{19-22}$. However, as registries expanded, the limitations of serological typing for HLA to discriminate variances that caused increases in immunologic toxicities impacting survival became apparent ${ }^{23,24}$. The early success of unrelated HCT was likely related to donors and recipients sharing common HLA haplotypes as these were the only possible donors identified through registries of limited size $e^{25}$. No hypothesis has been proven to explain why these outcomes were potentially better. Genes for several inflammatory cytokines are located on chromosome 6 between the class I and class II HLA genes; if those genes function differently in the setting of a common haplotype, this could potentially explain why these early results were better $^{25}$. A single base pair difference in HLA not detectable by serotyping can impact survival. Mismatches on more than one locus have an impact that is often more than the additive effects. With the advent of molecular HLA typing coupled with larger donor registries exceeding several million donors worldwide, the outcomes of unrelated HCT have been able to approximate those observed with HLA genotypic sibling matches ${ }^{26}$.

Transplant physicians felt a necessity to offer an allogeneic transplant donor option for every patient lacking a genotypically match sibling while simultaneously addressing the causes of treatment-related mortality. New donor options such as umbilical cord blood and the use of haploidentical donors have been increasingly being explored. Increasing HCT survival while expanding graft sources required the improvements in HCT pretransplant preparative regimens and infectious disease prevention and treatment, and addressing the causes of graft failure and rejection, graft-versus-host disease (GVHD), and relapse post allogeneic $\mathrm{HCT}^{27}$. In an effort to reduce organ toxicity of preparative regimen, reduced intensity regimens were developed, which allow HCT to be offered to patients aged more than 45 years and those with significant comorbidities. These regimens focused on obtaining durable engraftment with the graft providing the principal antitumor effect. In order to treat infectious diseases, collaboration with pharmaceutical firms yielded new antiviral and antifungal antibiotics targeting cytomegalovirus, respiratory syncytial virus, Candida albicans, and Aspergillus fumigates. Oftentimes, these new antiviral and antifungals were not only administered as treatments for active infections but also as prophylactic treatments. Addressing graft failure required not only improvement in preparative regimens and better selection of potential donors, but also testing to better measure the quality of the hematopoietic stem cells being infused. The field transitioned from measuring total nucleated cells to using flow cytometry. These flow cytometric measures were particularly important when using umbilical cord blood donor and haploidentical donor products where primary and secondary graft failure remain a significant risk. For GVHD, the most effective preventative strategy was ex-vivo T-cell depletion. Better techniques were developed for cell separation with less loss of hematopoietic progenitors. More recently, newer immunosuppressive agents were developed as well as novel administrative methods for older drugs. Post HCT relapse was initially impacted by the use of donor-derived $\mathrm{T}$ lymphocyte addbacks ${ }^{28,29}$. Now, genetically engineered cellular addbacks specific for targeting antigens on malignant cell surface are available. New pharmaceutical agents targeting specific alterations in tumor cell gene have recently become available. Knowledge on HLA typing has also improved and is being used to determine certain donors with a lower relapse rate ${ }^{30}$.

\section{Improved Success by Overcoming Immunological Barriers}

Acute and chronic GVHD remain a problem, and the severity of acute GVHD is associated with poorer survival. Historically, most of the efforts were focused on the prevention of GVHD as treatment options were limited. T-cell depletion was the most effective preventative strategy, which reduces the impact of HLA mismatches. T-cell depletion even allowed transplants to be successful without performing other pharmaceutical interventions. However, T-cell depletion was associated with increased risk of graft rejection, relapse, and infectious complications $^{31,32}$. In the mismatched setting, use of T-cell depletion did not increase the risk for relapse ${ }^{33}$. For unrelated HCT, HLA complete molecular matching at HLA A, B, and C; DR loci; and possible DP and DQ loci minimized the risk of GVHD, which improved survival without the use of T-cell depletion ${ }^{34,35}$. The impact of molecular typing was observed in all unrelated HCT populations but was greatest in those populations where impact of minor histocompatibility mismatching was less.

Patients with rare HLA haplotypes and those of mixed ethnic ancestry experience difficulties in finding unrelated donors. Their need are not often met even with the use of unrelated umbilical cord bloods as graft sources, despite umbilical cord bloods allowing more mismatching between donors and recipients ${ }^{36}$. A pioneering approach with an aggressive T-cell depletion and the use of peripheral blood progenitor cells improved the outcomes of patients receiving haploidentical transplants. Since parents and children are haploidentical matches, most patients in need of an allogeneic HCT require such donors. More recently, two approaches have been predominantly used in haploidentical transplantation: the use of post-transplant cyclophosphamide as pioneered by the 
John Hopkins group and the Beijing group's G-CSF mobilization, intensified immunosuppression, anti-thymocyte globulin administration, and combination of donor bone marrow and peripheral blood stem cells obtained by apheresis (GIAC) approach ${ }^{37}$. The Hopkins approach essentially creates a partially T-cell depleted graft using post-transplant cyclophosphamide to stunt $\mathrm{T}$ cell proliferation ${ }^{38}$. This approach has been effective in patients with high risk of graft failure such as those with aplastic anemia ${ }^{39}$. However, it can cause problems with immune reconstitution, relapse, and congestive heart failure in older patients. The use of allogeneic donor T-lymphocyte infusion can increase the risk of developing severe GVHD when obtained even at lower dose from a haploidentical donor. This regimen has been utilized in combination with non-myeloablative preparatory regimens. The GIAC regimen has become popular in Asia ${ }^{40}$. It has been utilized as an intensive preparatory regimen, which involves the use of cyclophosphamide, busulfan, Me-CCNU, and cytarabine, and combined with immunosuppressive agents such as antithymocyte globulin, cyclosporine, methotrexate, and mycophenolate. Recently, the GIAC regimen has also been utilized with a less intensive preparatory regimen. The GIAC regimen has been primarily used in populations that may have lesser risk of acute GVHD due to less heterogeneity in minor histocompatibility antigen. More recently, the Lu Daopei hospitals has presented intriguing data regarding the use of GIAC regimen to consolidate remissions obtained after low-dose infusion of autologous chimeric antigen receptor T-cells. The preferred donors for those requiring haploidentical HCT with GIAC in Beijing were haploidentical cousins.

With the emergence of ex-vivo T-cell depletion technology and post-transplant cyclophosphamide being effective in reducing the risk of acute GVHD, both may be useful as an initial platform for HCT with post-transplant add-on therapies. These transplant techniques are associated with increased relapse risk; however, this risk could be mitigated using a targeted molecular therapy where available, which inhibits FLT-3, IDH 1, IDH2, JAK 1, JAK 2, JAK 3, and BCR-ABL. The long-term use of targeted molecular therapy may not be required after functional donor T lymphocyte reconstitution occurs. Another alternative approach could be use chimeric antigen receptor $\mathrm{T}$ lymphocytes or NK cells being given as a bridging anti-tumor effect until functional donor T-cell and NK cell immunity are reconstituted ${ }^{41}$. The use of allogenic chimeric antigen receptor remains intriguing, but infusing activated allogeneic immune effectors can cause GVHD. Infusing targeted alloreactive T lymphocytes or NK cells with either a suicide gene like Caspace-9 remains under active investigation ${ }^{42}$.

The advent of research in systemic and organ-specific biomarkers has given new insights into GVHD in terms of its initiation and exacerbation ${ }^{43}$. With a better understanding on the regulatory inflammatory processes, new therapies have been recently tested and approved for treatment of GVHD including ruxolitinib and ibrutinib $^{44,45}$. B lymphocytes have been shown in vitro to impact $\mathrm{T}$ lymphocyte signaling and development of $\mathrm{T}$ lymphocyte subsets. This impact of B lymphocytes on $\mathrm{T}$ lymphocyte regulatory pathways is supported by the results of an observational study on B lymphocyte depletion drugs and B lymphocyte signaling inhibitors as treatment for GVHD, particularly in sex-mismatched $\mathrm{HCT}^{46,47}$. Novel cellular therapy agents such as mesenchymal stem cells have been shown to induce local tissue tolerance ${ }^{48,49}$. This therapy has been effective in treating gut GVHD and preventing GVHD ${ }^{50}$.

\section{Future Areas of Research}

Sex-mismatched allogeneic HCT provides a unique irrefutable marker for tracking cell differentiation. This has demonstrated the ability of bone marrow-derived stem cells to differentiate into skin cell, hepatocytes, vascular endothelial cells, and potentially cardiac myo$\operatorname{cytes}^{51}$. This knowledge has raised even more questions, i.e., if local stem cells are regenerating tissues, why do transplant survivors develop end organ dysfunction? Will stem cell transplantation help treat future chronic diseases like chronic obstructive pulmonary disease, vascular disease, and idiopathic pulmonary fibrosis ${ }^{52,53}$ ? Will the HCT physicians be able to manipulate and augment immune surveillance of HCT to reduce relapse risk? No single HCT center and possibly single country registry, will have sufficient patient observations to do all the science needed. Collaboration, particularly international collaboration, is necessary for answering these scientific questions to allow the HCT field to progress and expand. HCT is often performed in patients with a terminal disease before basic science could provide a full physiological understanding of the clinical observation. Historically, a paradigm for this was made (an unrelated donor HCT where the initial success approximated HLA genotypic match sibling data). The early success fostered a clinical overreach as the HCT field suddenly realized that HLA serotyping was insufficient for the selection of donors. This propelled the usage of molecular HLA typing techniques and development of even larger registries that gave rise to the current success with the use of unrelated donor HCT.

\section{HCT Global Collaboration}

Essential to the HCT field's advancement was Mortimer Bortin's development of an international registry for 
worldwide sharing of HCT outcomes and determination of the correlation between patient and donor characteris$\operatorname{tics}^{54}$. The original International Bone Marrow Transplantation Registry, now called the Center for International Blood and Marrow Transplantation Research(CIBMTR), included HCT centers from every continent ${ }^{55}$. The outcomes of over 450,000 HCT recipients are have been recorded in the database. For the past 10 years, over 1,000 peer-reviewed articles have been published ${ }^{56}$ CIBMTR in 2001 helped sponsor a clinical trials network with 10 core centers and over 80 affiliated centers ${ }^{57,58}$. This resulted in the conduct of several landmark prospective trials that could have never been performed at any single center or even in a single country ${ }^{59,60}$. Associated with CIBMTR are the international donor registries with over 32 million volunteer donors and over 750,000 cord blood units. Recently, CIBMTR has received a NIH grant to capture outcomes data for genetically modified cellular therapy as required by the Food and Drug Administration. International centers have been invited to submit outcomes data as well.

The HCT field has recognized the need for self-regulation. The American Society for Blood and Marrow Transplantation in association with the International Society of Cellular Therapy in 1995 collaborated in initiating the Foundation for the Accreditation of Cellular Therapy (FACT) to develop universal standards and guidelines for assessing HCT centers in the US and Canada ${ }^{61}$. At the time, the FACT recommended a novel approach to determine the standards necessary for maintaining quality, which was assessing and measuring an HCT program as an integrated unit rather than evaluating the components of facilities and providers. Thus, the FACT assessed the HCT centers' integrated facilities management program including collection, cell processing, and treatment as well as their staff, including physicians, nurses, pharmacists, medical engineers, and data managers. At its inception, the FACT guidelines emphasized that monitoring and measuring the effects of clinical guidelines on patients' outcomes was essential for maintaining quality. The FACT-accredited programs included the collection of local data on patient outcomes and participation in international and international data sharing and outcomes analysis. The FACT and ISCT collaborated with the European Society for Blood and Marrow Transplantation (EBMT) to have common standards with the Joint Accreditation Committee for International Society for Cellular Therapy (ISCT) and Europe (JACIE). The FACT and JACIE collaborated to establish a common method of accrediting a new genetically modified cellular therapy.

Other areas of international collaboration have included the donor registries, umbilical cord blood banks, international clinical trials, and cell repositories. The international access to stem cell donors despite the availability of patients and donors from native countries have been an unqualified success. This has enabled the most common type of transplant to move from related to unrelated HCT. Procedures have been developed to allow unhindered transfer emergently of hematopoietic progenitor cells across international boundaries. There has been access to patient- and donor-related materials in the cell repositories allowing molecular analysis of histocompatibility risk factors for transplantation that could not be performed in a single country. International collaboration has extended to prospective clinical trials. Most recently, there have been international discussions on the need for standardization for quality assurance testing of products and for standardization of potency determination. Without such standardization, product interchangeability will be severely compromised.

Clinical advancements in HCT has been made prior to the basic scientific explanations of the observed clinical efficacy. This was due to the imperative to provide urgent treatments to extremely sick and dying patients. Initial success sometimes led to the clinical overreach as what happened with unrelated donor transplants, which gained success in the late 1980s where the transplants likely involved donor and recipient pairs sharing common haplotypes. The expansion of donor registries and the high treatment-related mortality in the early 1990s highlighted the limitations of donor selection through serological typing. Molecular subtyping enabled the identification of alleles that are not demonstrable by serologic typing. Outcomes research demonstrated that patients' survival was improved with the use of a selection of donors. Mortimer Bortin's development of an outcome registry enabled transplants to advance rapidly as centers mostly performed phase 2 clinical trials.

\section{New Directions in a Changing Environment for HCT Research and Collaboration}

Over the decades, the clinicians have greatly learned from their experience handling transplant patients and donors. In the field of HCT, a team-based care is required to maintain the quality of medical interventions. The pioneers of this field must be honored and remembered for the seeds they planted that resulted in hundreds of thousands of lives being saved and prolonged. This field advanced rapidly due to international collaboration of donor registries especially in terms of sharing of HCT outcomes. CIBMTR enabled the determination of important risks and the factors that can predict HCT survival and toxicities. The international cooperation of unrelated donor registries allowed the worldwide sharing of donor grafts. To continue its march forward, HCT as a field cannot let international boundaries be barriers to common quality assurance standards and potency definitions. The 
outcomes registries must also include those of immune effector cells. Personalized medicine may limit the ability to gain insights from large randomized clinical trials, making the usage of HCT outcomes registries even more vital. The costs of therapy will now have to be considered and could be a new limitation. The HCT field need to understand the drivers of costs and resource consumption in the treatment of patients. Again, the international collaboration will lend perspective unobtainable from a single country's health economic system. The historical international collaboration of HCT will enable HCT to continue to strive forward for the good of the patients and clinical and scientific research. With the advent of new products such as genetically modified immune effector cell therapy, the HCT field must establish common definitions of products to ensure proper utilization and development. Fortunately, the international organizational structures in both CIBMTR and the self-accreditation agencies like FACT are well established and functioning to allow this to happen.

\section{Conflict of Interest}

The author declares no conflict of interest. A disclosure form provided by the author is available here.

\section{References}

1. Niederwieser D, Baldomero H, Szer J, Gratwohl M, Aljurf M, Atsuta $Y$, et al. Hematopoietic stem cell transplantation activity worldwide in 2012 and a SWOT analysis of the Worldwide Network for Blood and Marrow Transplantation Group including the global survey. Bone Marrow Transplant. 2016; 51: 77885.

2. Thomas E. Marrow Transplantation for Malignant Diseases. Journal of Clinical Oncology. 1975; 1: 514-31.

3. O’Reilly RJ. Allogenic bone marrow transplantation: current status and future directions. Blood. 1983; 62: 941-64.

4. Horowitz MM, Gale RP, Sondel PM, Goldman JM, Kersey J, Kolb HJ, et al. Graft-versus-leukemia reactions after bone marrow transplantation. Blood. 1990; 75: 555-62.

5. Bortin MM, Horowitz MM, Gale RP. Current status of bone marrow transplantation in humans: report from the International Bone Marrow Transplant Registry. Nat Immun Cell Growth Regul. 1988; 7: 334-50.

6. Gratwohl A, Baldomero H, Aljurf M, Pasquini MC, Bouzas LF, Yoshimi A, et al. Hematopoietic stem cell transplantation: a global perspective. JAMA. 2010; 303: 1617-24.

7. Joshua TV, Rizzo JD, Zhang MJ, Hari PN, Kurian S, Pasquini $\mathrm{M}$, et al. Access to hematopoietic stem cell transplantation: effect of race and sex. Cancer. 2010; 116: 3469-76.

8. Gratwohl A, Baldomero H, Gratwohl M, Aljurf M, Bouzas LF, Horowitz M, et al. Quantitative and qualitative differences in use and trends of hematopoietic stem cell transplantation: a Global Observational Study. Haematologica. 2013; 98: 128290.

9. Appelbaum FR. The current status of hematopoietic cell transplantation. Annu Rev Med. 2003; 54: 491-512.

10. Aschan J. Allogeneic haematopoietic stem cell transplantation: current status and future outlook. Br Med Bull. 2006; 77-78: 23-36.

11. CIBMTR. CIBMTR Annual Report 2018. https://www.cib mtr.org/About/AdminReports/Documents/2018Annual Report.pdf/ [Accessed October 31, 2019]

12. Bortin MM, Atkinson K, van Bekkum DW, Biggs JC, Dicke KA, Gale RP, et al. Factors influencing the risk of acute and chronic graft-versus-host disease in humans: a preliminary report from the IBMTR. Bone Marrow Transplant. 1989; 4 Suppl 1: 222-4.

13. Lu DP. Syngeneic bone marrow transplantation for treatment of aplastic anaemia: report of a case and review of the literature. Exp Hematol. 1981; 9: 257-63.

14. Gale RP, Horowitz MM, Ash RC, Champlin RE, Goldman JM, Rimm AA, et al. Identical-twin bone marrow transplants for leukemia. Ann Intern Med. 1994; 120: 646-52.

15. Beatty PG, Clift RA, Mickelson EM, Nisperos BB, Flournoy N, Martin PJ, et al. Marrow transplantation from related donors other than HLA-identical siblings. N Engl J Med. 1985; 313: 765-71.

16. Ash RC, Casper JT, Chitambar CR, Hansen R, Bunin N, Truitt RL, et al. Successful allogeneic transplantation of T-celldepleted bone marrow from closely HLA-matched unrelated donors. N Engl J Med. 1990; 322: 485-94.

17. Gajewski JL, Ho WG, Feig SA, Hunt L, Kaufman N, Champlin RE. Bone marrow transplantation using unrelated donors for patients with advanced leukemia or bone marrow failure. Transplantation. 1990; 50: 244-9.

18. Beatty PG, Ash R, Hows JM, McGlave PB. The use of unrelated bone marrow donors in the treatment of patients with chronic myelogenous leukemia: experience of four marrow transplant centers. Bone Marrow Transplant. 1989; 4: 287-90.

19. Cleaver SA. The Anthony Nolan Research Centre. Bone Marrow Transplant. 1993; 11 Suppl 1: 38-40.

20. Beatty PG, Dahlberg S, Mickelson EM, Nisperos B, Opelz G, Martin PJ, et al. Probability of finding HLA-matched unrelated marrow donors. Transplantation. 1988; 45: 714-8.

21. Sonnenberg FA, Eckman MH, Pauker SG. Bone marrow donor registries: the relation between registry size and probability of finding complete and partial matches. Blood. 1989; 74: 256978.

22. McCullough J, Rogers G, Dahl R, Therkelsen D, Kamstra L, Crisham P, et al. Development and operation of a program to obtain volunteer bone marrow donors unrelated to the patient. Transfusion. 1986; 26: 315-23.

23. Kernan NA, Bartsch G, Ash RC, Beatty PG, Champlin R, Filipovich A, et al. Analysis of 462 transplantations from unrelated donors facilitated by the National Marrow Donor Program. N 
Engl J Med. 1993; 328: 593-602.

24. Flomenberg N, Baxter-Lowe LA, Confer D, Fernandez-Vina M, Filipovich A, Horowitz M, et al. Impact of HLA class I and class II high-resolution matching on outcomes of unrelated donor bone marrow transplantation: HLA-C mismatching is associated with a strong adverse effect on transplantation outcome. Blood. 2004; 104: 1923-30.

25. Petersdorf EW, Malkki M, Horowitz MM, Spellman SR, Haagenson MD, Wang T. Mapping MHC haplotype effects in unrelated donor hematopoietic cell transplantation. Blood. 2013; 121: 1896-905.

26. Horowitz MM. Does matched unrelated donor transplantation have the same outcome as matched sibling transplantation in unselected patients? Best Pract Res Clin Haematol. 2012; 25: 483-6.

27. Young JH, Logan BR, Wu J, Wingard JR, Weisdorf DJ, Mudrick $\mathrm{C}$, et al. Infections after Transplantation of Bone Marrow or Peripheral Blood Stem Cells from Unrelated Donors. Biol Blood Marrow Transplant. 2016; 22: 359-70.

28. Kolb HJ, Mittermuller J, Clemm C, Holler E, Ledderose G, Brehm G, et al. Donor leukocyte transfusions for treatment of recurrent chronic myelogenous leukemia in marrow transplant patients. Blood. 1990; 76: 2462-5.

29. Mackinnon S, Papadopoulos EB, Carabasi MH, Reich L, Collins $\mathrm{NH}$, Boulad F, et al. Adoptive immunotherapy evaluating escalating doses of donor leukocytes for relapse of chronic myeloid leukemia after bone marrow transplantation: separation of graft-versus-leukemia responses from graft-versus-host disease. Blood. 1995; 86: 1261-8.

30. Petersdorf EW, Gooley T, Malkki M, Horowitz M, International Histocompatibility Working Group in Hematopoietic Cell T. Clinical significance of donor-recipient HLA matching on survival after myeloablative hematopoietic cell transplantation from unrelated donors. Tissue Antigens. 2007; 69 Suppl 1: 25-30.

31. Goldman JM, Gale RP, Horowitz MM, Biggs JC, Champlin RE, Gluckman E, et al. Bone marrow transplantation for chronic myelogenous leukemia in chronic phase. Increased risk for relapse associated with T-cell depletion. Ann Intern Med. 1988; 108: 806-14.

32. Gajewski JL, Nimer S, Saliba RM, Thomas M, Przepiorka D, Giralt S, et al. Long-term outcome of a phase II study of BM transplants, partially depleted ex-vivo of CD5-positive and CD8-positive T-lymphocytes in unrelated and related donor 1 antigen mismatched recipients. Cytotherapy. 1999; 1: 401-7.

33. Ash RC, Horowitz MM, Gale RP, van Bekkum DW, Casper JT, Gordon-Smith EC, et al. Bone marrow transplantation from related donors other than HLA-identical siblings: effect of T cell depletion. Bone Marrow Transplant. 1991; 7: 443-52.

34. Gajewski J, Gjertson D, Cecka M, Tonai R, Przepiorka D, Hunt $\mathrm{L}$, et al. The impact of T-cell depletion on the effects of HLA DR beta 1 and DQ beta allele matching in HLA serologically identical unrelated donor bone marrow transplantation. Biol Blood Marrow Transplant. 1997; 3: 76-82.
35. Lee SJ, Klein J, Haagenson M, Baxter-Lowe LA, Confer DL, Eapen M, et al. High-resolution donor-recipient HLA matching contributes to the success of unrelated donor marrow transplantation. Blood. 2007; 110: 4576-83.

36. Eapen M, Kurtzberg J, Zhang MJ, Hattersely G, Fei M, Mendizabal A, et al. Umbilical Cord Blood Transplantation in Children with Acute Leukemia: Impact of Conditioning on Transplantation Outcomes. Biol Blood Marrow Transplant. 2017; 23: $1714-21$.

37. Ciurea SO, Zhang MJ, Bacigalupo AA, Bashey A, Appelbaum FR, Aljitawi OS, et al. Haploidentical transplant with posttransplant cyclophosphamide vs matched unrelated donor transplant for acute myeloid leukemia. Blood. 2015; 126: 1033-40.

38. Klein OR, Buddenbaum J, Tucker N, Chen AR, Gamper CJ, Loeb D, et al. Nonmyeloablative Haploidentical Bone Marrow Transplantation with Post-Transplantation Cyclophosphamide for Pediatric and Young Adult Patients with High-Risk Hematologic Malignancies. Biol Blood Marrow Transplant. 2017; 23: $325-32$.

39. DeZern AE, Zahurak M, Symons H, Cooke K, Jones RJ, Brodsky RA. Alternative Donor Transplantation with High-Dose Post-Transplantation Cyclophosphamide for Refractory Severe Aplastic Anemia. Biol Blood Marrow Transplant. 2017; 23: 498-504.

40. Apperley J, Niederwieser D, Huang XJ, Nagler A, Fuchs E, Szer J, et al. Haploidentical Hematopoietic Stem Cell Transplantation: A Global Overview Comparing Asia, the European Union, and the United States. Biol Blood Marrow Transplant. 2016; 22: 23-6.

41. Lu. P-h. Car-T treatment for refractory relapsed B-cell ALL in China[abstract]. Blood Cell Therapy. Abstracts. ABSTRACTS from the 23rd Annual Congress of APBMT (PDF): 287. https://bct.apbmt.org/abstracts/ [Accessed October 31, 2019]

42. Zhou X, Dotti G, Krance RA, Martinez CA, Naik S, Kamble RT, et al. Inducible caspase-9 suicide gene controls adverse effects from alloreplete $\mathrm{T}$ cells after haploidentical stem cell transplantation. Blood. 2015; 125: 4103-13.

43. Alahmari SB, Choi J, Cooper M, Vij K, Ritchey J, Wang B, et al. Elective Inhibition of $\alpha 4 \beta 1$ Integrin (VLA-4) Mitigates GvHD. Blood. 2016; 128: 3344.

44. Zeiser R, Burchert A, Lengerke C, Verbeek M, Maas-Bauer K, Metzelder S, et al. Treatment of Corticosteroid-Refractory Graft-Versus-Host Disease with Ruxolitinib in 95 Patients. Blood. 2015; 126: 858.

45. Cutler CS, Koreth J, Ritz J. Mechanistic approaches for the prevention and treatment of chronic GVHD. Blood. 2017; 129: $22-9$.

46. Kharfan-Dabaja MA, Cutler CS. Rituximab for prevention and treatment of graft-versus-host disease. Int J Hematol. 2011; 93: 578-85.

47. Miklos D, Cutler C, Arora M, Walker E, Jagasia M, Nakamura $\mathrm{R}$, et al. Multicenter open-label phase $1 \mathrm{~b} / 2$ study of ibrutinib in steroid-dependent/refractory chronic graft versus host dis- 
ease (cGVHD) [abstract]. Bone Marrow Transplantation. 2016; 51 Suppl S1: S176-7.

48. Burrows GG, Van't Hof W, Newell LF, Reddy A, Wilmarth PA, David LL, et al. Dissection of the human multipotent adult progenitor cell secretome by proteomic analysis. Stem Cells Transl Med. 2013; 2: 745-57.

49. Maziarz RT. Mesenchymal stromal cells: potential roles in graft-versus-host disease prophylaxis and treatment. Transfusion. 2016; 56: 9S-14S.

50. Maziarz RT, Devos T, Bachier CR, Goldstein SC, Leis JF, Devine SM, et al. Single and multiple dose MultiStem (multipotent adult progenitor cell) therapy prophylaxis of acute graftversus-host disease in myeloablative allogeneic hematopoietic cell transplantation: a phase 1 trial. Biol Blood Marrow Transplant. 2015; 21: 720-8.

51. Korbling M, Katz RL, Khanna A, Ruifrok AC, Rondon G, Albi$\operatorname{tar} \mathrm{M}$, et al. Hepatocytes and epithelial cells of donor origin in recipients of peripheral-blood stem cells. N Engl J Med. 2002; 346: 738-46.

52. Yeh ET, Zhang S, Wu HD, Korbling M, Willerson JT, Estrov Z. Transdifferentiation of human peripheral blood CD34 + enriched cell population into cardiomyocytes, endothelial cells, and smooth muscle cells in vivo. Circulation. 2003; 108: 2070-3.

53. Amado LC, Saliaris AP, Schuleri KH, St John M, Xie JS, Cattaneo S, et al. Cardiac repair with intramyocardial injection of allogeneic mesenchymal stem cells after myocardial infarction. Proc Natl Acad Sci U S A. 2005; 102: 11474-9.

54. Rimm AA, Barr JT, Horowitz MM, Bortin MM. Use of a clinical data registry to evaluate medical technologies. Experience from the International Bone Marrow Transplant Registry. Int J Technol Assess Health Care. 1991; 7: 182-93.
55. Horowitz MM. The role of the International Bone Marrow Transplant Registry in assessing clinical efficacy. Leukemia. 1993; 7: 1106.

56. Horowitz MM, Loberiza FR, Bredeson CN, Rizzo JD, Nugent ML. Transplant registries: guiding clinical decisions and improving outcomes. Oncology (Williston Park). 2001; 15: 649-59.

57. Khera N, Majhail NS, Brazauskas R, Wang Z, He N, Aljurf MD, et al. Comparison of Characteristics and Outcomes of Trial Participants and Nonparticipants: Example of Blood and Marrow Transplant Clinical Trials Network 0201 Trial. Biol Blood Marrow Transplant. 2015; 21: 1815-22.

58. Appelbaum FR, Anasetti C, Antin JH, Atkins H, Davies S, Devine $S$, et al. Blood and marrow transplant clinical trials network state of the Science Symposium 2014. Biol Blood Marrow Transplant. 2015; 21: 202-24.

59. Horowitz MM. The Blood and Marrow Transplant Clinical Trials Network: An Effective Infrastructure for Addressing Important Issues in Hematopoietic Cell Transplantation. Biol Blood Marrow Transplant. 2016; 22: 1747-57.

60. Weisdorf D, Carter S, Confer D, Ferrara J, Horowitz M. Blood and marrow transplant clinical trials network (BMT CTN): addressing unanswered questions. Biol Blood Marrow Transplant. 2007; 13: 257-62.

61. FACT. About FACT, Foundation for the Accreditation of Cellular Therapy. http://www.factwebsite.org/AboutFACT/ [Accessed October 31, 2019]

https://doi.org/10.31547/bct-2019-016

Copyright (C) 2020 APBMT. All Rights Reserved. 